\title{
AVALIAÇÃO DA COMPOSIÇÃO FÍSICO-QUÍMICA E ROTULAGEM DE DIFERENTES MARCAS DE LEITE UHT INTEGRAL
}

Rodrigo Alves de Sousa ${ }^{1}$, Dayana Silva Batista Soares ${ }^{2}$, Ellen Godinho Pinto ${ }^{2}$, Brenda Ventura de Lima e Silva ${ }^{3}$

${ }^{1}$ Discente do curso Superior de Tecnologia em Alimentos do IFGoiano-campus Morrinhos; ${ }^{2}$ Docente da área de Alimentos do IFGoiano-campus Morrinhos; ${ }^{3}$ Técnica Administrativa em Educação do IFGoiano-campus Morrinhos. Email: dayana.soares@ifgoiano.edu.br

\section{RESUMO}

O leite é um alimento muito importante na alimentação humana, graças ao seu conteúdo nutritivo. Considera-se leite UAT (Ultra Alta Temperatura) ou UHT (Ultra High Temperature), o leite homogeneizado submetido, durante 2 a 4 segundos, a uma temperatura 130 C a 150 ㅇ C. Dentre os diversos componentes do leite estão a água, em maior quantidade, gordura, proteínas e carboidratos. Objetivou-se avaliar leites UHT integral, de marcas comercializadas na região sul de Goiás, quanto as suas características físico-químicas e comparar os resultados com os padrões da legislação vigente bem como avaliar o rótulo quanto a rotulagem geral e nutricional. Para a avaliação da qualidade físico-química do leite UHT avaliou-se índice crioscópico, densidade, acidez titulável, pH, teor de gordura e extrato seco total (EST) e desengordurado (ESD). Os resultados foram comparados com os padrões de qualidade estabelecidos pela legislação. Os rótulos das amostras foram analisados quanto a legislação no que se refere a rotulagem geral, rotulagem nutricional, informações quanto a alergias e intolerâncias. As amostras analisadas apresentaram

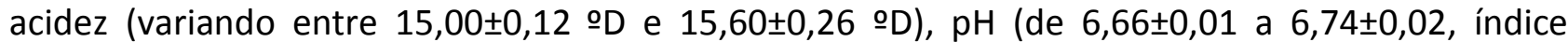
crioscópio $(-0,555 \pm 0,003$ a $-0,538 \pm 0,002)$, extrato seco desengordurado $(8,35 \pm 0,14 \%$ a $8,83 \pm 0,03 \%)$, densidade $(1,029 \pm 1,270 \mathrm{~g} / \mathrm{L}$ a $1,032 \pm 0,461)$ em consonância com a legislação, bem como a rotulagem. As marcas B, C e D apresentaram valores médios de gordura; $2,9 \pm 0,06 \%$, $2,9 \pm 0,13 \%, 2,80 \pm 0,12 \%$, respectivamente; abaixo do previsto pela legislação e apenas a marca $B$ apresentou menor valor de EST $(11,25 \pm 0,09 \%)$ que a legislação.

Palavras-chave: qualidade; embalagem; rotulagem geral; rotulagem nutricional.

\section{EVALUATION OF THE PHYSICAL-CHEMICAL COMPOSITION AND LABELING OF DIFFERENT BRANDS OF UHT INTEGRAL MILK}

\begin{abstract}
Milk is a very important food in human food, thanks to its nutritious content. UAT (Ultra High Temperature) or Ultra High Temperature (UHT) milk is the homogenised milk that has been submitted for 2 to 4 seconds at a temperature of $130^{\circ} \mathrm{C}$ to $150^{\circ} \mathrm{C}$. Among the various components of milk are water, In greater quantity, fat, proteins and carbohydrates. The objective of this study was to evaluate UHT whole milk milks, commercial brands in the southern region of Goiás, as well as their physico-chemical characteristics and to compare the results with the current legislation standards and the information contained in the labels. To evaluate the physicochemical quality of the UHT milk, it was evaluated cryoscopic index, density, titratable acidity, pH, fat content and total dry extract (EST) and defatted (ESD). The results were compared with the quality standards established by the legislation. Sample labels were reviewed for legislation on general labeling, nutritional labeling, allergy and intolerance information. The samples analyzed
\end{abstract}




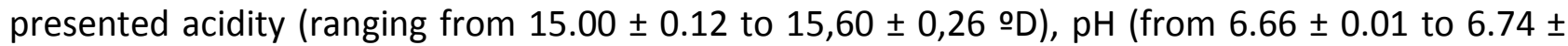
0.02 , cryoscope index $(-0.535 \pm 0.003$ at $-0.538 \pm 0.002)$, dry extract defatted $(8.35 \pm 0.14 \%$ at 8.83 $\pm 0.03 \%)$, density $(1.029 \pm 1.270 \mathrm{~g} / \mathrm{L}$ at $1.032 \pm 0.461)$ in accordance with $\mathrm{B}, \mathrm{C}$ and $\mathrm{D}$ presented mean values of fat, $2.9 \pm 0.06 \%, 2.9 \pm 0.13 \%$, and $2.80 \pm 0.12 \%$, respectively, below. Of the legislation and only the B mark had a lower EST value $(11.25 \pm 0.09 \%)$ than the legislation.

Keywords: quality, packing, General labeling, nutrition labeling 


\section{INTRODUÇÃO}

O leite constitui-se de uma mistura homogênea com grande número de substâncias e nutrientes, das quais alguns destes nutrientes e substâncias estão em emulsão (lipídeos e substâncias associadas), alguns em suspensão (caseínas ligadas a sais), e outros em dissolução verdadeira (lactose, vitaminas hidrossolúveis, proteínas do soro, sais, etc) (ORDÓÑEZ, 2005).

Trata-se de um alimento muito rico nutricionalmente, composto por $87,3 \%$ de água e $12,7 \%$ de sólidos totais, distribuídos da seguinte forma: proteínas totais, 3,3 a 3,5\%, gordura, 3,5 a 3,8\%, lactose, 4,9\%, minerais, 0,7\% em média, além de vitaminas (SGARBIERI, 2005).

As análises físico-químicas que são realizadas no leite, durante sua recepção no laticínio e após processamento são de extrema importância para assegurar a qualidade do produto. O leite contém micro-organismos que podem mudar as características das análises físico-químicas, portanto, o seu monitoramento rotineiro é de extrema importância para garantir a inocuidade do produto (TRONCO, 2008).

A legislação vigente estabelece padrões físico-químicos para o leite UHT integral de mínimo de $3 \%$ de gordura, acidez titulável entre 14 e 18 이 (0,14 a 0,18 de acidez em gramas de ácido lático/100ml), estabilidade ao etanol a 68\%, no mínimo 8,2\% de ESD e pH 6,6 e 6,8 (BRASIL,1997).

Segundo BRASIL (1996), entende-se por leite UAT ou UHT (Ultra Alta Temperatura), o leite homogeneizado submetido durante 2 a 4 segundos, a uma temperatura 130 $\mathrm{C}$ a 150 ㅇ , mediante um processo térmico de fluxo contínuo, imediatamente resfriado a uma temperatura inferior a $32^{\circ} \mathrm{C}$ e embalado em condições assépticas em embalagens estéreis e hermeticamente fechadas.

Os equipamentos para produção de leite UHT são totalmente automatizadas. O sistema corresponde a quatro etapas: esterilização, produção, limpeza CIP (cleaning in place ou sistema em circuito fechado) e limpeza asséptica intermediária (TRONCO, 2008).

Em uma pesquisa realizada pela Associação Brasileira da Indústria do Leite Longa Vida (ABLV) identificou que o leite UHT está presente em $87 \%$ dos lares brasileiros, representando $76 \%$ do leite fluido de consumo e mais de $47 \%$ do total do leite consumido no Brasil (ABLV, 2009).

O leite UHT integral, pela sua conveniência, praticidade, diversidade e disponibilidade no mercado, contribuiu para a ampliação do comércio de leite de consumo do Brasil (FERNANDES, 2006; ROSSI-JÚNIOR et al., 2006; BERSOT et al., 2010; DOMARESKI et al., 2010; LIMA et al., 2012).

Agência Nacional de Vigilância Sanitária (ANVISA) no Brasil, através de diferentes Resoluções de Diretoria Colegiada (RDCs), determina quais são as informações nutricionais que devem estar nos rótulos dos alimentos para garantir a proteção da saúde dos consumidores (BASTOS et al., 2008). Além da rotulagem nutricional, os alimentos também devem atender a padrões de identidade e qualidade, estabelecidos pela legislação vigente, a fim de garantir ao consumidor o acesso a alimentos que não causem danos à saúde (LOBANCO, 2007).

Objetivou-se avaliar marcas de leites UHT integral, de marcas comercializadas na região sul de Goiás, quanto as suas características físico-químicas, comparando os resultados com os padrões da legislação vigente, além de avaliar o rótulo quanto a rotulagem geral e nutricional.

\section{MATERIAL E MÉTODOS}

As amostras de leite integral UHT foram adquiridas, de forma aleatória, em comércios locais da região sul de Goiás. Foram adquiridas cinco marcas diferentes de leite integral UHT sendo que as mesmas foram denominadas como: A, B, C, D e E para avaliação dos resultados das análises com a legislação vigente de diferentes lotes. Todas as amostras estavam dentro do prazo de validade.

O índice crioscópico foi determinado em crioscópio digital microprocessado (SILVA et al, 1997). A análise de densidade foi realizada com auxílio do termolactodensímetro. Já os resultados de $\mathrm{pH}$ foram obtidos com auxílio de um pHmetro (BRASIL, 2002). O teste de acidez titulável 
(Dornic) e determinação de determinação do teor de gordura (método de Gerber) foram realizados segundo Silva et al. (1997).

Na determinação do extrato seco total (EST) utilizou-se o método indireto, que consiste na aplicação de fórmula matemática de Furtado (Equação 1), a qual correlaciona valor de densidade e teor de gordura da amostra (BRASIL, 2002).

$\% E S T=1,2 \times G d+0,25 \times D+0,25$

Sendo: Gd: teor de gordura e D: densidade

O ESD (extrato seco desengordura) foi obtido da subtração do teor de gordura em relação ao extrato seco total conforme Equação 2 (BRASIL, 2002).

$\% E S D=\% E S T-G d$

Todas as análises físico-químicas foram realizadas em triplicata.

Para a comparação com os valores estabelecidos pela legislação seguiu-se o Regulamento Técnico de Identidade e Qualidade de Leite UHT (BRASIL, 1997). Os rótulos das amostras foram analisados conforme parâmetros estabelecidos pela Instrução Normativa no 259 de 2002 (BRASIL, 2002), RDC no 360 (BRASIL, 2003a), RDC no 359 (BRASIL, 2003b), Resolução no 54 de 2012 (BRASIL, 2012), Resolução no26 de 2015 (BRASIL, 2015) e Lei 13.350 de 2016 (BRASIL, 2016), sendo eles: Conteúdo; Nome ou Razão Social; Endereço; CNPJ; Carimbo do Sistema de Inspeção Oficial; Número de Registro no Sistema de Inspeção; Informações sobre cuidado e conservação do produto; Lote; Informações Nutricionais; Frase Obrigatória: "Este produto não deve ser usado para alimentar Crianças menores de 1 (um) ano de idade, a não ser por indicação expressa do médico ou nutricionista. O aleitamento materno evita infecções e alergias e deve ser mantido até a criança completar 2 (dois) anos de idade ou mais". Alérgicos Contém Leite.

A análise estatística dos resultados foi efetuada usando estatística descritiva (média \pm desvio padrão) e a comparação entre as médias foi realizada pelo teste de Tukey $(p \leq 0,05)$ utilizando o programa ASSISTAT versão 7.7 beta (SILVA; AZEVEDO, 2016).

\section{RESULTADOS E DISCUSSÃO}

De acordo com a Tabela 1, os valores médios do teor de acidez e pH para as 05 marcas não diferiram estatisticamente entre si, a nível de significância de 5\%, e estavam de acordo com os parâmetros de acidez estabelecidos pela legislação.

Tabela 1. Média dos resultados das análises físico-químicas (acidez, pH, gordura, crioscopia, densidade, EST e ESD) dos leites UHT integrais (A, B, C, D e E). Leite UHT Integral

\begin{tabular}{|c|c|c|c|c|c|}
\hline Parâmetros & A & B & $\mathrm{C}$ & D & $E$ \\
\hline Acidez (D) & $\begin{array}{l}15,100 \pm \\
0,082^{\mathrm{a}^{*}}\end{array}$ & $15,000 \pm 0,115^{a}$ & $\begin{array}{c}15,000 \pm \\
0,115^{\mathrm{a}}\end{array}$ & $\begin{array}{c}15,600 \pm \\
0,259^{\mathrm{a}}\end{array}$ & $\begin{array}{c}15,000 \pm \\
0,404^{\mathrm{a}}\end{array}$ \\
\hline $\mathrm{pH}$ & $6,730 \pm 0,018^{a}$ & $6,700 \pm 0,023^{a}$ & $\begin{array}{l}6,740 \pm \\
0,023^{a}\end{array}$ & $\begin{array}{l}6,660 \pm \\
0,008^{a}\end{array}$ & $6,670 \pm 0,012^{a}$ \\
\hline Gordura (\%) & $3,000 \pm 0,058^{a}$ & $2,900 \pm 0,058^{a}$ & $\begin{array}{l}2,900 \pm \\
0,129^{a}\end{array}$ & $\begin{array}{l}2,800 \pm \\
0,115^{a}\end{array}$ & $3,000 \pm 0,346^{a}$ \\
\hline $\begin{array}{l}\text { Crioscopia } \\
\text { (아) }\end{array}$ & $\begin{array}{c}-0,539 \pm \\
0,005^{a}\end{array}$ & $\begin{array}{c}-0,538 \pm \\
0,002^{a}\end{array}$ & $\begin{array}{c}-0,550 \pm \\
0,004^{a}\end{array}$ & $\begin{array}{c}-0,555 \pm \\
0,003^{a}\end{array}$ & $\begin{array}{c}-0,545 \pm \\
0,002^{a}\end{array}$ \\
\hline $\begin{array}{l}\text { Densidade } \\
(\mathrm{g} / \mathrm{L})\end{array}$ & $\begin{array}{l}1,030 \pm \\
0,258^{a}\end{array}$ & $\begin{array}{l}1,029 \pm \\
1,270^{a}\end{array}$ & $\begin{array}{l}1,032 \pm \\
0,461^{a}\end{array}$ & $\begin{array}{l}1,032 \pm \\
0,115^{a}\end{array}$ & $\begin{array}{l}1,031 \pm \\
0,925^{a}\end{array}$ \\
\hline EST (\%) & $11,500 \pm 0,096^{a}$ & $\begin{array}{c}11,250 \pm \\
0,087^{\mathrm{a}}\end{array}$ & $\begin{array}{c}11,650 \pm \\
0,103^{a}\end{array}$ & $\begin{array}{c}11,660 \pm \\
0,139^{\mathrm{a}}\end{array}$ & $\begin{array}{c}11,600 \pm \\
0,174^{\mathrm{a}}\end{array}$ \\
\hline ESD (\%) & $8,470 \pm 0,071^{a}$ & $8,350 \pm 0,144^{a}$ & $\begin{array}{l}8,790 \pm \\
0,104^{a}\end{array}$ & $\begin{array}{l}8,830 \pm \\
0,029^{a}\end{array}$ & $8,620 \pm 0,162^{a}$ \\
\hline
\end{tabular}


*Letras iguais na mesma linha não diferem entre si pelo teste de Tukey $(p \leq 0,05)$.

A legislação estabelece que acidez titulável do leite UHT integral deve estar entre 14 e 18 oD e pH variando entre 6,6 a 6,8 (BRASIL, 1997). A acidez do leite pode aumentar através da hidrólise da lactose, por enzimas microbianas que levam a formação de ácido lático, e se a acidez for muito alta, o leite é considerado impróprio para o consumo, pois indica atividade microbiana. A acidez do leite, também, pode diminuir devido à ação do tratamento térmico, e esta diminuição é que leva o leite a coagulação (LIMA et al., 2009).

Martins et.al. (2008), analisaram 30 amostras do leite UHT, em uma indústria do estado de São Paulo -SP. Das amostras de leite UHT, apenas uma apresentou resultado de $\mathrm{pH}=6,4$ e o restante das amostras mantiveram-se dentro dos valores de referência de pH 6,6 a 6,8. Andrioli et al. (2004) analisaram 50 amostras de leite UHT de 15 marcas diferentes comercializadas em Juiz de Fora (MG). Das 50 amostras analisadas, 12 apresentaram valores de acidez fora do padrão.

Segundo Foschiera (2004) conhece-se a qualidade de um leite pela dosagem de gordura, sendo que esta é um dos componentes de maior valor comercial. A determinação de gordura no leite é uma das maneiras de se identificar fraudes no alimento, como o desnate prévio do leite, adição de água. A legislação vigente estabelece que o leite UHT integral de possuir no mínimo de $3 \%$ de gordura (BRASIL, 1997).

As amostras analisadas não diferiram entre si pelo teste estatístico utilizado, porém observa-se que as marcas $A$ e $E$ apresentaram todos os resultados dentro do previsto pela legislação. Já as amostras das marcas B, C e D apresentaram teor de gordura médio abaixo do estabelecido pela legislação, com destaque para a marca $D$ que apresentou menor valor. $O$ teor de gordura diminui em função da padronização (3\%) que o leite sofre antes da pasteurização (MARTINS et al., 2008). Bersot et al. (2010) analisaram 150 amostras de leite UHT integral de três marcas comercializadas em Palotina (PR) e $29 \%$ das amostras tiveram o teor de gordura em desacordo com a legislação vigente. No estudo de Camara e Weschenfelder (2014) 100\% das amostras encontraram-se de acordo com os parâmetros mínimos de gordura.

$\mathrm{Na}$ análise do índice crioscópico, as amostras não diferiram entre si e estão em acordo com os padrões vigentes, de $-0,530^{\circ} \mathrm{H}$ a $-0,560^{\circ} \mathrm{H}$ (BRASIL, 1997). Os resultados indicam não haver fraude no leite pela adição de água.

A Instrução Normativa no 62/2011 (BRASIL, 2011), estabelece a densidade deve estar entre 1,028 a 1,034 g/mL para o leite cru refrigerado e sua avaliação é de grande importância para saber se houve ou não fraudes. A densidade pode ser modificada por adição de água ou desnatação prévia, visto que a água tem uma densidade maior que a gordura, respectivamente $1 \mathrm{~g} / \mathrm{cm}^{3}$ e $0,9301 \mathrm{~g} / \mathrm{cm}^{3}$ (CASTRO, 2005). Todas as amostras analisadas estavam dentro dos padrões exigidos pela legislação e não diferiram entre si a $5 \%$ de significância.

Robim et al. (2012), analisando a densidade a 15 oc de cinquenta e oito amostras de diferentes marcas de leite UHT integral, observaram alguns resultados menores aos deste estudo, cuja a média encontrada foi de 1,029 a 1,030 g/mL. Da mesma forma Domareski et al. (2010), verificando a densidade a 15 o C de oito amostras de várias marcas de leite UHT integral, constaram variações de 1,028 a $1,029 \mathrm{~g} / \mathrm{mL}$.

Em relação ao EST, as diferentes marcas de leite UHT integral apresentaram valores entre $11,25 \%$ e 11,66\%. A Instrução Normativa no 62/2011 (BRASIL, 2011), estabelece-se um mínimo de $11,5 \%$ para o leite cru refrigerado, com isso, observa-se que apesar da média dos resultados não apresentarem diferença entre si pelo teste estatístico utilizado, a marca B está abaixo do estabelecido pela legislação. Os resultados deste trabalho estão abaixo dos resultados encontrados por Camara e Weschenfelder, 11,59 a 12,13\% (2014).

Para Martins et al. (2008) o teor de gordura diminui em função da padronização (3\%) que o leite sofre antes da pasteurização bem como os valores da densidade, do EST e do ESD. 
Já os valores médios de ESD estavam entre $8,35 \%$ e $8,83 \%$, ou seja, apresentaram um mínimo de 8,2\%, como estabelecido pela legislação (BRASIL, 1997). Em concordância com este estudo estão os resultados encontrados por Camara e Weschenfelder (2014) e Tamanini et al. (2011), com o objetivo de analisar o ESD de dezessete amostras de diferentes marcas de leite UHT integral, verificaram que todas as amostras estavam de acordo com o padrão estabelecido pela legislação.

Em São José do Rio Preto, Martins et al. (2008) avaliaram os efeitos do processamento UHT (Ultra Alta Temperatura) sobre as características físico-químicas do leite e observaram que todas as amostras obedeceram aos parâmetros gordura e acidez, porém, com relação ao ESD nenhuma das amostras atendeu ao estabelecido pela legislação brasileira.

Os rótulos das amostras foram analisados quanto a legislação ao que se referem a rotulagem geral, rotulagem nutricional, informações quanto a alergias e intolerâncias. Todas as 5 marcas estavam de acordo com os parâmetros analisados.

Do ponto de vista da defesa do consumidor, a rotulagem dos alimentos visa disponibilizar informações corretas, claras, precisas e ostensivas sobre o produto, devem ser escritas em língua portuguesa, apresentando suas características, quantidade, composição, garantia, prazos de validade e origem, entre outros dados, bem como sobre os riscos que possam apresentar à saúde e segurança dos consumidores (MACHADO, 2015).

\section{CONCLUSÃO}

Todas as amostras analisadas estão em consonância com a legislação quanto a acidez, pH, índice crioscópio, extrato seco desengordurado e densidade. Em relação a porcentagem de gordura as marcas B, C e D e em relação ao extrato seco total apenas a marca B apresentaram resultados abaixo do previsto pela legislação. Apesar de apresentarem valores médios abaixo do previsto não pôde-se inferir que trata-se de amostras fraudadas, uma vez que os valores encontram-se bem próximos aos previstos.

Quanto a rotulagem, $100 \%$ das amostras apresentaram-se dentro dos padrões estabelecidos pela legislação comparada.

\section{REFERÊNCIAS}

ANDRIOLI, A. S.; FURTADO, M. A. M.; VILELA, M. A. P.; MEURER, V. M. Padrões físico-químicos de identidade e qualidade do leite "Longa vida" (UHT) comercializado na cidade de Juiz de Fora, MG. Revista do Instituto de Laticínios Candido Tostes, Juiz de Fora, v.59, [s.n.], p.50-54, 2004.

ASSOCIAÇÃO BRASILEIRA DA INDÚSTRIA DO LEITE LONGA VIDA (ABLV). Leite longa vida está presente em 87\% dos lares brasileiros. 2009. Disponível em: www.ablv.org.br. Acesso em: 03 fev. 2017.

BASTOS, A. A.; BELINELLO, M. H.; SOUTO, A. C.; SARAIVA, T. C. C. Avaliação da qualidade sanitária dos rótulos de alimentos embalados de origem animal. Revista Baiana de Saúde Pública, v. 32, n. 2, p. 218-231, 2008.

BERSOT, L. DOS S.; GALVÃO, J. A.; RAYMUNDO, N. L. R.; BARCELLOS, V. C.; PINTO, J. P. A. N.; MAZIERO. M. T. Avaliação microbiológica e físico-química de leites UHT produzidos no Estado do Paraná - Brasil. Seminário ciências agrárias, Londrina, v.31, n.3, p.645-652. 2010. https://doi.org/10.5433/1679-0359.2010v31n3p645 
BRASIL. Agência Nacional de Vigilância Sanitária. Lei no 13.305, de 4 de julho de 2016. Acrescenta art. 19-A ao Decreto-Lei no 986, de 21 de outubro de 1969, que "institui normas básicas sobre alimentos", para dispor sobre a rotulagem de alimentos que contenham lactose. Diário Oficial da República Federativa do Brasil, Brasília, 05 de julho de 2016.

BRASIL. Agência Nacional de Vigilância Sanitária. Resolução- RDC № 26, de 02 de julho de 2015. Dispõe sobre os requisitos para rotulagem obrigatória dos principais alimentos que causam alergias alimentares. Diário Oficial da República Federativa do Brasil, Brasília, 3 de julho de 2015.

BRASIL. Agência Nacional de Vigilância Sanitária. Resolução- RDC no 54, de 12 de novembro de 2012. Dispõe sobre o Regulamento Técnico sobre Informação Nutricional Complementar. Diário Oficial da República Federativa do Brasil, Brasília, 13 de novembro de 2012. .

BRASIL. Ministério da Agricultura, Pecuária e Abastecimento. Instrução Normativa no 62, de 29 de dezembro de 2011. Aprova o Regulamento Técnico de Produção, Identidade e Qualidade do Leite tipo A, o Regulamento Técnico de Identidade e Qualidade de Leite Cru Refrigerado, o Regulamento Técnico de Identidade e Qualidade de Leite Pasteurizado e o Regulamento Técnico da Coleta de Leite Cru Refrigerado e seu Transporte a Granel, em conformidade com os Anexos desta Instrução Normativa. Diário Oficial da República Federativa do Brasil, Brasília, 30 de dezembro de 2011.

BRASIL. Agência Nacional de Vigilância Sanitária. Resolução RDC $n^{\circ} 360$, de 23 de dezembro de 2003. Aprova Regulamento Técnico sobre Rotulagem Nutricional de Alimentos Embalados, tornando obrigatória a rotulagem nutricional. Diário Oficial da República do Brasil, Brasília, 26 de dezembro de 2003a.

BRASIL. Agência Nacional de Vigilância Sanitária. Resolução RDC no 359, de 23 de dezembro de 2003. Aprova Regulamento Técnico de Porções de Alimentos Embalados para Fins de Rotulagem Nutricional. Diário Oficial da República Federativa do Brasil, Brasília, 26 de dezembro de 2003b.

BRASIL, Ministério da Agricultura, Pecuária e Abastecimento. Instrução normativa no 51, de 18 de setembro de 2002. Departamento de Inspeção de Produto de Origem Animal. Aprova os Regulamentos Técnicos de Produção, Identidade e Qualidade do Leite tipo A, do Leite tipo B, do Leite tipo C, do Leite Pasteurizado e do Leite Cru Refrigerado e o Regulamento Técnico da Coleta de Leite Cru Refrigerado e seu Transporte a Granel. Diário Oficial da República Federativa do Brasil, Brasília, 20 de setembro de 2002.

BRASIL. Ministério da Agricultura e do Abastecimento. Portaria nำ146, de 07 de março de 1996, alterado pela Portaria no 370, de 04 de setembro de 1997. Regulamento Técnico de Identidade e Qualidade de Leite UAT. Diário Oficial da República Federativa do Brasil, Brasília, DF, 08 de setembro de 1997.

BRASIL. Ministério da Agricultura, Pecuária e Abastecimento. Aprovado pelo Decreto nํㅜ 1.255, de 25 de junho de 1962, alterado pelo Decreto no 1.812 de 08 de fevereiro de 1996. Regulamento Técnico de Identidade e Qualidade de Produtos Lácteos. Diário Oficial da República Federativa do Brasil, Brasília, 07 de março de 1996. .

CAMARA, F. A.; WESCHENFELDER, S. Leite UHT integral: avaliação da rotulagem nutricional e dos padrões de identidade e qualidade. Revista do Instituto de Laticínios Candido Tostes, Juiz de Fora, v. 69, n. 4, p. 268-279, 2014. https://doi.org/10.14295/2238-6416.v69i4.331 
CASTRO, P. de S. Apostila de aulas Práticas: Tecnologia de Leites e Derivados. Goiás: Universidade Católica de Goiás, 2005.

DOMARESKI, J. L.; BANDIERA, N. S., SATO, R. T.; ARAGON-ALEGRO L. C.; SANTANA, S. E. H. de Avaliação físico-química e microbiológica do leite UHT comercializado em três países do Mercosul (Brasil, Argentina e Paraguai). Archivos Latinoamericanos de Nutricion, Caracas, v. 60, n. 3, 2010.

FERNANDES, A. M. Estudo comparativo entre leite pasteurizado e leite UHT. 2006. 46 p. Trabalho de Conclusão de Curso (PósGraduação Lato Sensu em Higiene e Inspeção de Produtos de Origem Animal e Vigilância Sanitária em Alimentos) - Universidade Castelo Branco. Rio de Janeiro, 2006.

FOSCHIERA, J.L. Indústria de Laticínios. $1^{\circ}$ ed. Porto Alegre: Suliane, 2004, $88 \mathrm{p}$.

LIMA, F. M.; BRUNINI, M. A.; MACIEL JÚNIOR, V. A.; MORANDIN, C. S. RIBEIRO, C. T. Qualidade de leite UHT integral e desnatado, comercializado na cidade de São Joaquim da Barra,SP. Nucleus Animalium, v.1, n.1, maio 2009.

LIMA, N. K. P.; SILVA, D. M. B. DA; RAMIREZ, E. A. DOS. S.; REGIS, K. G.; CASTRO, M. L. L. DE; SILVA, S. M. da. Análises físico-químicas de amostras de leite UHT integral comercializados no município de Morrinhos, GO. Revista de Biotecnologia e Ciência, v. 2, n. 1, p. 93-102, 2012.

LOBANCO, C. M. Rotulagem nutricional de alimentos salgados e doces consumidos por crianças e adolescentes. 2007. 92 f. Dissertação (Mestrado em Saúde Pública) - Universidade de São Paulo, São Paulo. https://doi.org/10.11606/D.6.2007.tde-12052008-140337

MACHADO, R. L. P. Manual de rotulagem de alimentos. Rio de Janeiro: Embrapa Agroindústria de Alimentos, 2015.

MARTINS, A. M. C. V.; ROSSI JUNIOR, O. D.; SALOTTI, B. M.; BÜRGER, K. P.; CORTEZ, M. L. L.; CARDOZO, M. V. Efeito do processamento UAT (Ultra Alta Temperatura) sobre as características físico-químicas do leite. Ciência e Tecnologia de Alimentos, Campinas, v.28, n.2, p.295-298, 2008. https://doi.org/10.1590/S0101-20612008000200005

ORDÓÑEZ, J. A. Tecnologia de Alimentos: Alimentos de Origem Animal. v.2. Porto Alegre: Artmed, 2005.

ROBIM, M. S.; CORTEZ, M. A. S.; SILVA, A. C. de O.; FILHO, R. de A. T.; GEMAL, N. H.; NOGUEIRA, E. B. Pesquisa de fraude no leite UAT integral comercializado no estado do Rio de Janeiro e comparação entre os métodos de análises físico-químicas oficiais e o método de ultrassom. Instituto de Laticínios Cândido Tostes, v. 67, n. 389, p. 43-50, 2012. https://doi.org/10.5935/2238$\underline{6416.20120077}$

ROSSI-JÚNIOR, O. D.; VIDAL-MARTINS, A. M. C.; SALOTTI, B. M.; BÜRGER, K. P.; CARDOZO, M. V.; CORTEZ, A. L. L. Estudo das características microbiológicas do leite UAT ao longo de seu processamento. Arquivos do Instituto Biológico, v. 73, n. 1, p. 27-32, 2006.

SGARBIERI, V. C., Revisão: Propriedades estruturais e físico-químicas das proteínas do leite. Brazilian Journal of Food Technology, v.8, n.1, p. 43-56, 2005. 
SILVA, F. A. S.; AZEVEDO, C. A. V. The Assistat Software Version 7.7 and its use in the analysis of experimental data. African Journal of Agricultural Research, v. 11, n. 39, p. 3733-3740, 2016. https://doi.org/10.5897/AJAR2016.11522.

SILVA, P. H. F. ; PEREIRA, D. B. C. ; OLIVEIRA, L. L. ; COSTA JUNIOR, L. C. G. . Físico-química do leite e derivados - métodos analíticos. 1. ed. Juiz de Fora: Oficina de Impressão Gráficas e Editora Ltda; 1997

TAMANINI, R.; BELOTI, V.; RIBEIRO JUNIOR, J. C.; SILVA, L. C. C. da; YAMADA, A. K.; SILVA, F. de A. S. Contribuição ao estudo da qualidade microbiológica e físico-química do leite UHT. Revista do Instituto de Laticínios Cândido Tostes, v. 66, n. 382, p. 27-33, 2011.

TRONCO, M. Manual para Inspeção da Qualidade do Leite. 3ạ ed. Santa Maria: UFSM, 2008. 